\title{
Visceral pressure stimulator for exploring hollow organ pain: a pilot study
}

\author{
Michael DeLong ${ }^{1}$, Mauricio Gil-Silva ${ }^{1,2}$, Veronica Minsu Hong ${ }^{1}$, Olivia Babyok ${ }^{2}$ and Benedict J. Kolber ${ }^{1 *}$
}

\author{
*Correspondence: \\ benedict.kolber@utdallas.edu \\ ${ }^{1}$ Center for Advanced \\ Pain Studies, Department \\ of Neuroscience, University \\ of Texas at Dallas, $800 \mathrm{~W}$ \\ Campbell Rd., Richardson, TX \\ 75080, USA \\ Full list of author information \\ is available at the end of the \\ article
}

\begin{abstract}
Background: The regulation and control of pressure stimuli is useful for many studies of pain and nociception especially those in the visceral pain field. In many in vivo experiments, distinct air and liquid stimuli at varying pressures are delivered to hollow organs such as the bladder, vagina, and colon. These stimuli are coupled with behavioral, molecular, or physiological read-outs of the response to the stimulus. Care must be taken to deliver precise timed stimuli during experimentation. For example, stimuli signals can be used online to precisely time-lock the stimulus with a physiological output. Such precision requires the development of specialized hardware to control the stimulus (e.g., air) while providing a precise read-out of pressure and stimulus signal markers.

Methods: In this study, we designed a timed pressure regulator [termed visceral pressure stimulator (VPS)] to control air flow, measure pressure (in $\mathrm{mmHg}$ ), and send stimuli markers to online software. The device was built using a simple circuit and primarily off-the-shelf parts. A separate custom inline analog-to-digital pressure converter was used to validate the real pressure output of the VPS.
\end{abstract}

Results: Using commercial physiological software (Spike2, CED), we were able to measure mouse bladder pressure continuously during delivery of unique air stimulus trials in a mouse while simultaneously recording an electromyogram (EMG) of the overlying abdominal muscles.

Conclusions: This device will be useful for those who need to (1) deliver distinct pressure stimuli while (2) measuring the pressure in real-time and (3) monitoring stimulus on-off using physiological software.

Keywords: Bladder pain, Timed pressure regulator, Visceral pain, Colorectal pain

\section{Background}

Visceral pain includes acute and chronic pain associated with the viscera (e.g., internal organs). There are a number of unique characteristics of visceral pain that set it apart from somatic pain including unique sets of nociceptors, the presence of silent nociceptive neurons, and the phenomenon of referred pain [1,2]. Chronic visceral pain conditions include irritable bowel syndrome, chronic prostatitis, and chronic pelvic pain syndromes. The economic impact varies across the conditions, but can reach up 1.35 
billion US dollars per year [3]. Five percent of women are thought to be at risk of chronic pelvic pain, and chronic prostatitis affects $4.5-9 \%$ of men in the United States [4, 5]. These disorders are difficult to treat and many have unknown etiology. Animals (e.g., mice, rats, cats) provide critical models to understand and ultimately treat chronic visceral pain conditions. Numerous challenges exist in the study of visceral pain in animals. One of the biggest challenges is the method used to stimulate the visceral organ. Unlike somatic structures that can be easily accessed from the body surface, visceral structures must be stimulated with internal methods.

For vaginal, bladder, and rectal studies, the most common method involves inserting a catheter or balloon into the organ. This catheter or balloon is then connected to an air tank or pump to deliver air or liquid (e.g., water or saline) to the organ. Simultaneously, researchers measure the physiological, behavioral, and molecular impacts of this stimulation. For example, in the urinary bladder distention (UBD) visceromotor response (VMR) model, a mouse or rat's bladder is catheterized (typically female animals only) through the urethra [6, 7]. Distensions with graded air pressure (from 15 to $75 \mathrm{mmHg}$ ) induce corresponding graded reflexive contractions of the overlying abdominal muscles. These contractions can be quantified using an electromyogram (EMG) and are used as an indirect measure of pain-like responses to the stimulus. In human volunteers, similar stimuli induce graded feelings of discomfort and pain [8]. That is, low pressures are only mildly discomfortable while high pressures are described as painful. A necessary component of such studies is the ability to accurately measure pressure, closely control stimulus on/off, and time-lock stimuli to physiological measurements (e.g., VMR). A number of devices have been designed over the years with the first publication of such a remotely controlled device in 1987 [9]. The current manuscript describes a modern re-design of this device using off-the shelf equipment to reliably control stimuli pressure on/off gating, accurately measure pressure during stimulation, and provide stimulus markers for online time-locking of stimuli to physiological measures. The device was used to measure pain-like responses to bladder distention in an anesthetized mouse.

\section{Results}

\section{VPS build}

In this experiment, we sought to build a modern pressure regulator that would allow us to easily control pressure stimuli for use in animal models of visceral pain. We designed the system, the Visceral Pressure Stimulator (VPS; Fig. 1a) to have a pinch valve to gate the air stimulus, an analog-to-digital pressure sensor to accurately read the pressure when the pinch valve was "open", and a stimulus marker output function. The stimulus marker function included a marker at the pre-distention start and during the entire pinch valve open time period (Fig. 4a). The system is fully controllable via the standard representational state transfer (REST) web protocol. We included a prototype graphical user interface (GUI) based on Python3 and PyQt5 which exposes the REST-based control to a simple GUI. The GUI (Fig. 1b) allows the researcher to control the length of the pre-distention interval, the distention trial length and the intertrial interval. The system can also be set to run in loops for multiple trials in a row. The circuit diagram for the build can be seen in Fig. 2. The VPS was designed and built using off-the-shelf components and open-source software. The primary processor board in the system is a 


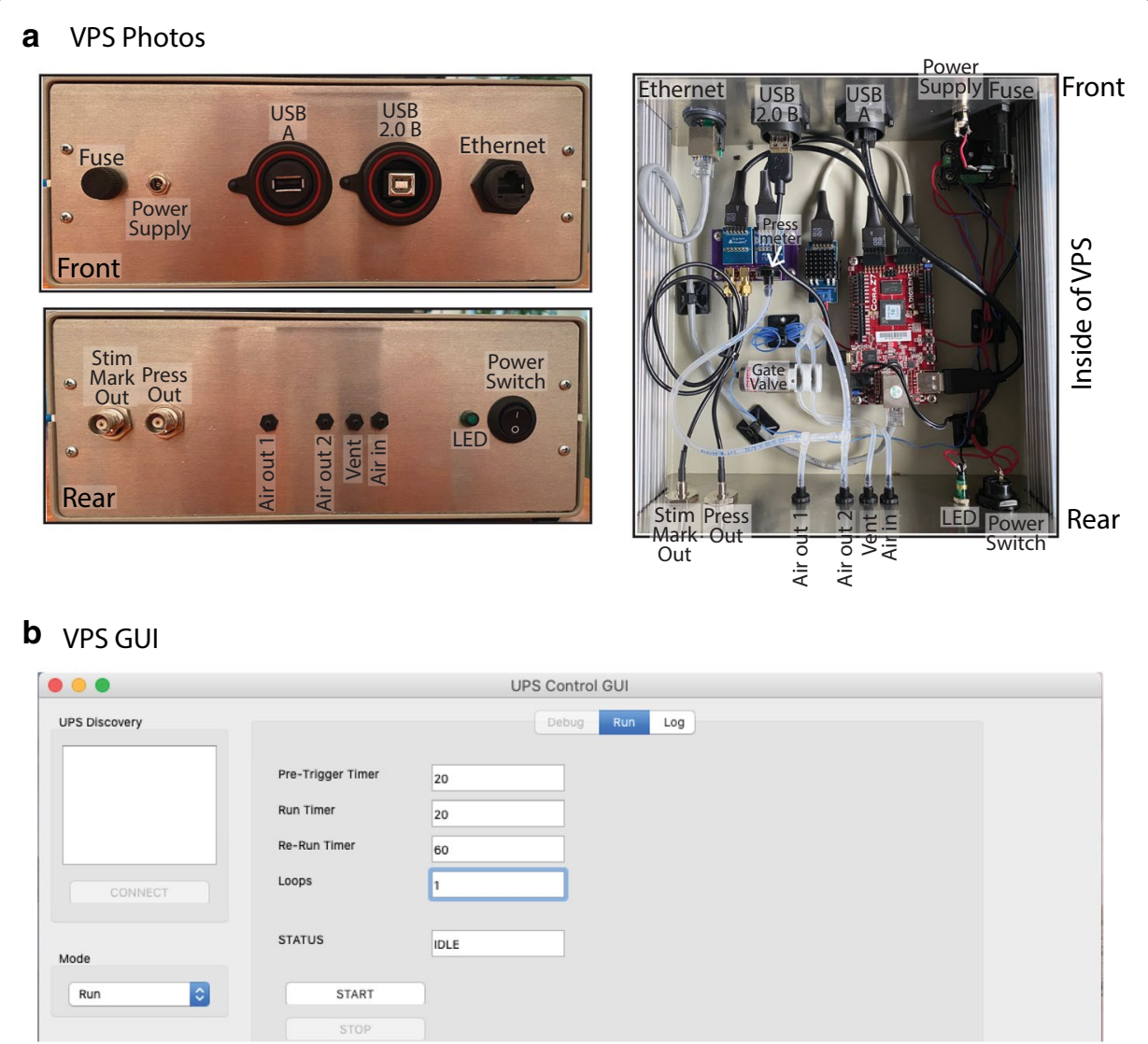

Fig. 1 Photo montage of VPS and GUI for VPS control. a Photos showing front, rear, and inside of VPS device (with individual parts labeled). b Screen shot of GUI for VPS control. Controls allow the user to set the pre-trial interval (set to $20 \mathrm{~s}$ in example), the length of an actual pressure trial (set to $20 \mathrm{~s}$ in example), the length of the intertrial interval (set to $60 \mathrm{~s}$ in example), and the number of trials to be run ("loops")

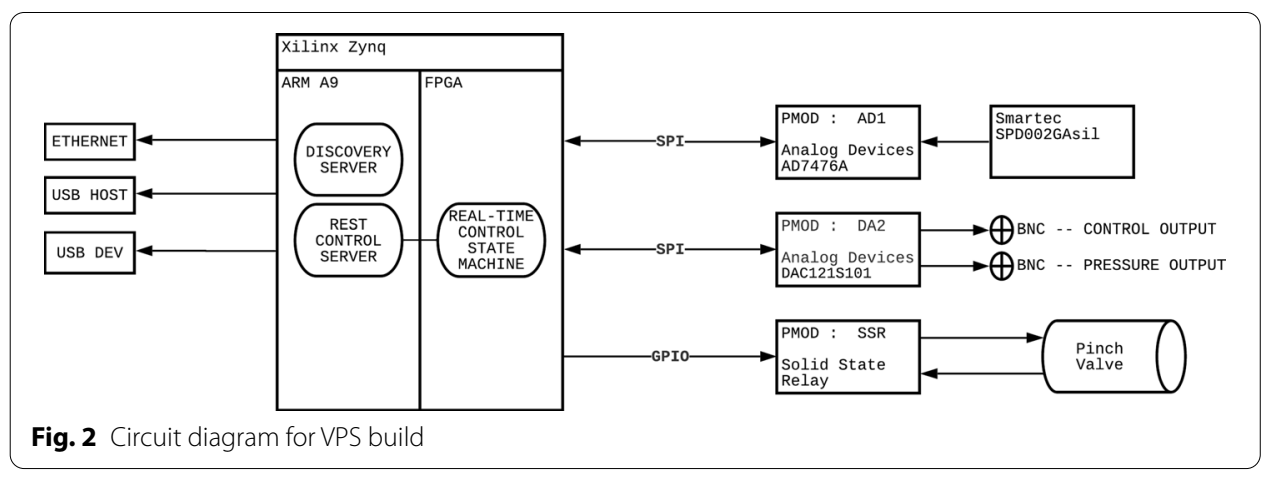

Digilent Cora Z7 which features the Xilinx Zynq 7000 processor. This board allows for connections to Arduino shields and Pmod boards in addition to standard PC interfaces. The Xilinx Zynq part has a die coupled dual core ARM A9 processor and field-programmable gate array (FPGA). The VPS uses a full custom embedded Linux distribution which facilitates standard Ethernet and USB external connections that are utilized in the 
VPS. The FPGA is programmed to handle the real-time aspects of the system including the analog-to-digital (ADC) and digital-to-analog (DAC) for air pressure measurement, the BNC based voltage outputs that interface to the larger system and the pinch valve. Standard Pmod boards were used for ADC, DAC, and pinch valve control with minor modifications for packaging.

\section{Testing of VPS in a mouse model of bladder pain}

To evaluate the potential of the VPS for visceral nociception testing, we utilized the mouse UBD-VMR procedure (Fig. 3). In this model, we catheterized the bladder of an anesthetized female mouse. The catheter is connected to the VPS allowing discrete stimuli to be applied to the bladder. The goal of this demonstration experiment was to show the utility of the VPS interface in directing different stimulus parameters to the mouse. We tested $20 \mathrm{~s} 30 \mathrm{mmHg}$ pressure trials using the VPS with an intertrial interval of $60 \mathrm{~s}$ and three loops. The initial air pressure was set using an analog sphygmometer upstream of the VPS. The pressure was set to "30 mmHg". As can be seen in Table 3, the actual pressure read was $\sim 31 \mathrm{mmHg}$ which is in manufacturer's tolerance range of the upstream analog sphygmometer $( \pm 3 \mathrm{mmHg})$. Pressure was measured using three

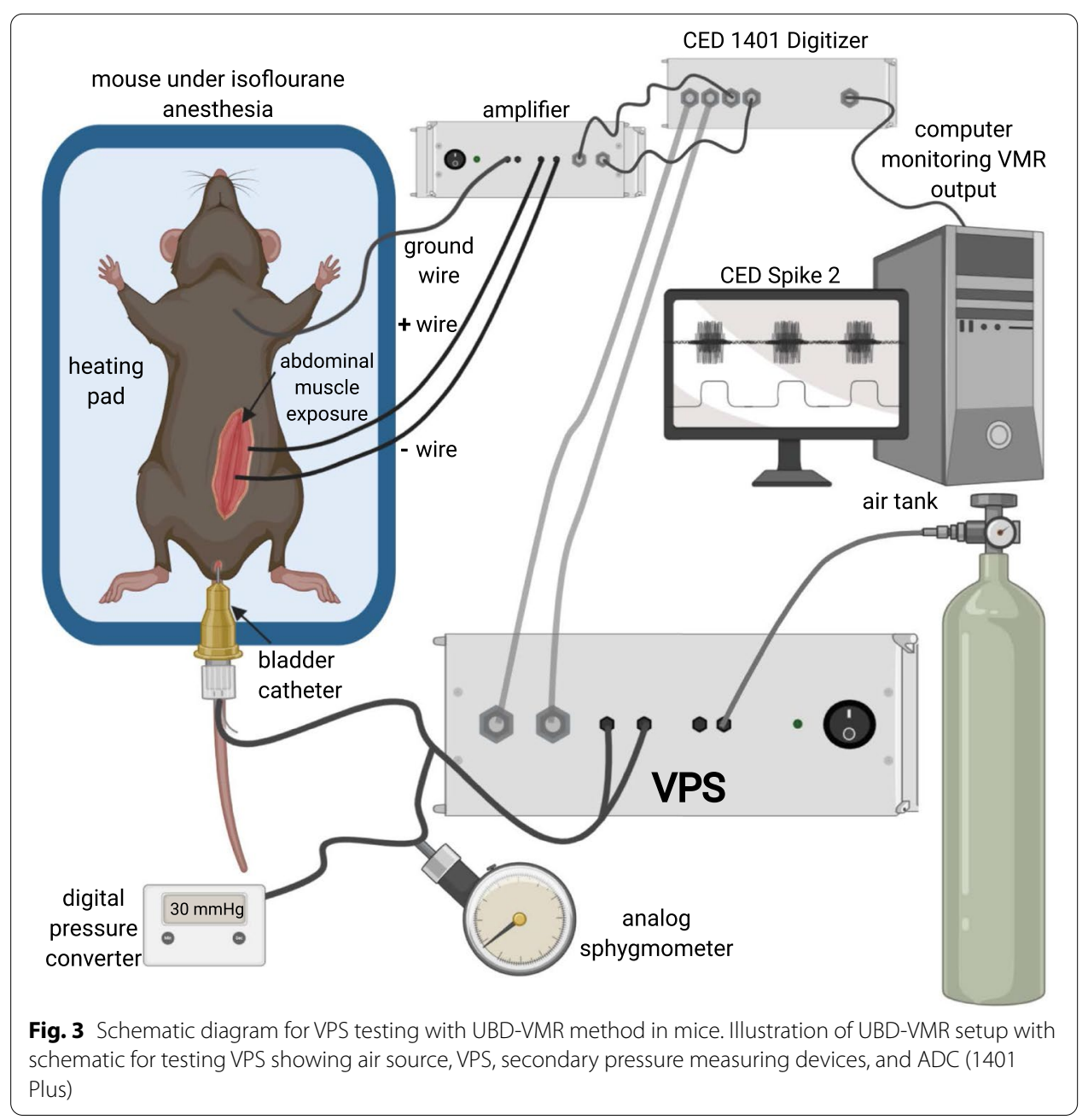


different methods. This included a second analog commercial sphygmometer downstream of the VPS, a custom inline analog-to-digital pressure converter downstream of the VPS, and the pressure sensor in the VPS. Spike 2 was used to record (1) the stimulus markers from the VPS (Fig. 4a) (2) the electromyogram (EMG) of the abdominal muscles overlying the bladder (Fig. 4b) (3) pressure from the VPS (Fig. 4c), and (4) pressure from an additional custom analog-to-digital pressure converter (Fig. $4 \mathrm{~d}$ ). The stimulus marker function included two markers. The first is a $2 \mathrm{~V}$ signal that begins at the start of each pre-distention trial and lasts for $1 \mathrm{~s}$. The second $1 \mathrm{~V}$ marker begins $20 \mathrm{~s}$ after the pre-distention marker and lasts for $20 \mathrm{~s}$ in these distention trials. In other words, the $1 \mathrm{~V}$ signal is a marker indicating when the pressure pinch valve on the VPS (see Fig. 1a) is open. The EMG to bladder distention occurs shortly following stimulus start as pressure increases. There is a slight delay in the EMG response due to (1) the time it takes for air to fill the tubing and urinary bladder once the VPS pinch valve opens ( $1 \mathrm{~s})$ and (2) the time it takes for the in vivo spinal reflex system to register the distention and induce muscle contractions $(\sim 1 \mathrm{~s})$. The total delay is actually variable between mice since it includes both the standard time for air to reach the bladder and the biological response of the animal to the stimulus (i.e., bladder distended, sensory neuron activated, spinal cord interneuron activated, efferent reflex initiated). For the demonstration trials, the delay was $\sim 2 \mathrm{~s}$ total. Similarly, as the custom converter is downstream of the VPS controller, there is a slight lag in the registered pressure both at stimulus on and stimulus off. The analog sphygmometer was manually observed and the pressure was noted half way through each trial. There was strong correlation between the VPS pressure sensor and the custom converter (Table 3). Following testing, a custom script in Matlab was used to convert the raw EMG signal into a normalized visceromotor response (VMR) during each distention trial; the script also calculates the average pressure during each trial (Table 3).

Following the initial development of the VPS, we initiated a period of real-world usage of the machine in the laboratory. Over the course of 2 months, we tested 18 female mice utilizing pressures ranging from 15 to $75 \mathrm{mmHg}$ depending on the specific experimental parameter. Across these studies, we completed 1200 total trials using both Macintoshand Windows-based computers to run the VPS. To assess whether the pressure of the VPS ran true to the pressure detected by our analog-to-digital converter, we extracted 20 trials from three separate mice. Pressure recordings from the VPS and analog-to-digital converter were analyzed for intra-rater reliability. The intra-class correlation coefficient $(\mathrm{ICC})$ between $30 \mathrm{mmHg}$ pressure readings was $0.98(P<0.0001)$ and the ICC between $60 \mathrm{mmHg}$ pressure readings was $0.99(P<0.0001)$ suggesting excellent reliability (ICC $>0.9$ ) of pressure readings across multiple trials and testing days (i.e., different animals) (Fig. 5).

\section{Discussion and conclusions}

Visceral pain is challenging to treat, in part, due to the lack of known mechanisms for human disease. In order to investigate these mechanisms, it is necessary to study visceral nociception in animal models. For hollow organ studies (e.g., bladder, vagina, rectum), the ability to precisely deliver pressure stimuli is critical. In this experiment, we designed a modern pressure regulator, the visceral pressure stimulator (VPS), to control pressure 


\section{a}

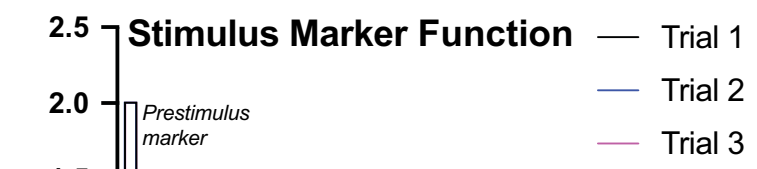

$\stackrel{n}{ \pm}$

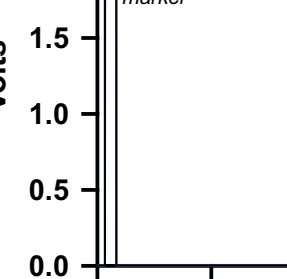

Start

- Trial 3

b

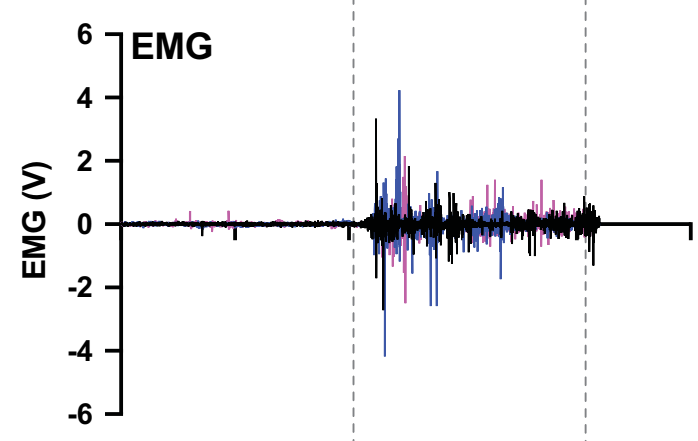

C

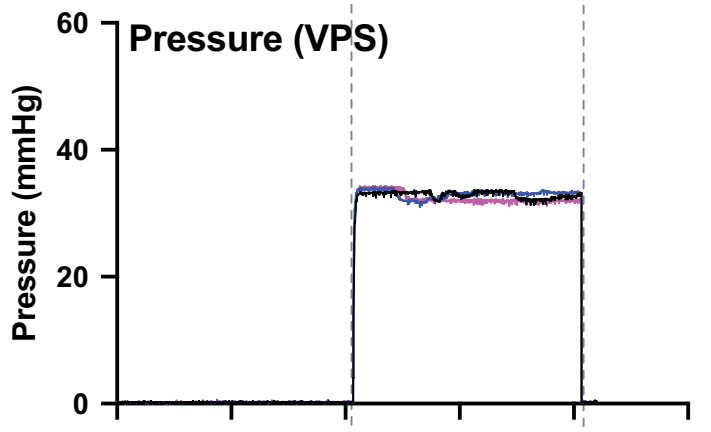

d

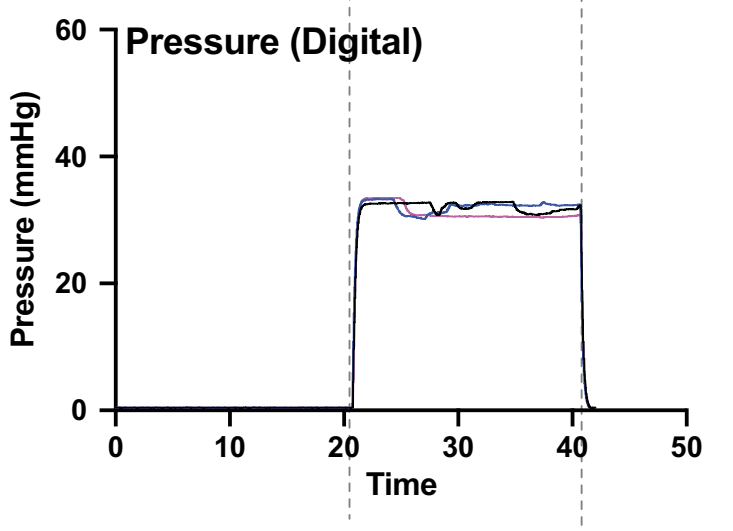

Fig. 4 Demonstration of three UBD-VMR trials of $20 \mathrm{~s}$ at $30 \mathrm{mmHg}$. All trials were controlled with the VPS GUI. a Plot is the stimulus marker function (from VPS) showing $2 \mathrm{~V}$ pre-stimulus marker along with $1 \mathrm{~V}$ stimulus marker. $\mathbf{b}$ Plot of raw EMG (volts) showing bladder distention evoked increase in EMG signal after stimulus start and tapering off of signal at stimulus end. $\mathbf{c}$ Plot of pressure $(\mathrm{mmHg})$ read from VPS. $\mathbf{d}$ Plot of pressure read from inline analog-to-pressure converter. Initial pressure setting was set using an analog sphygmometer to be at "30 mmHg" connected to an analog air valve. Pressure setting was not adjusted between trials. Plots were matched to pre-stimulus marker 

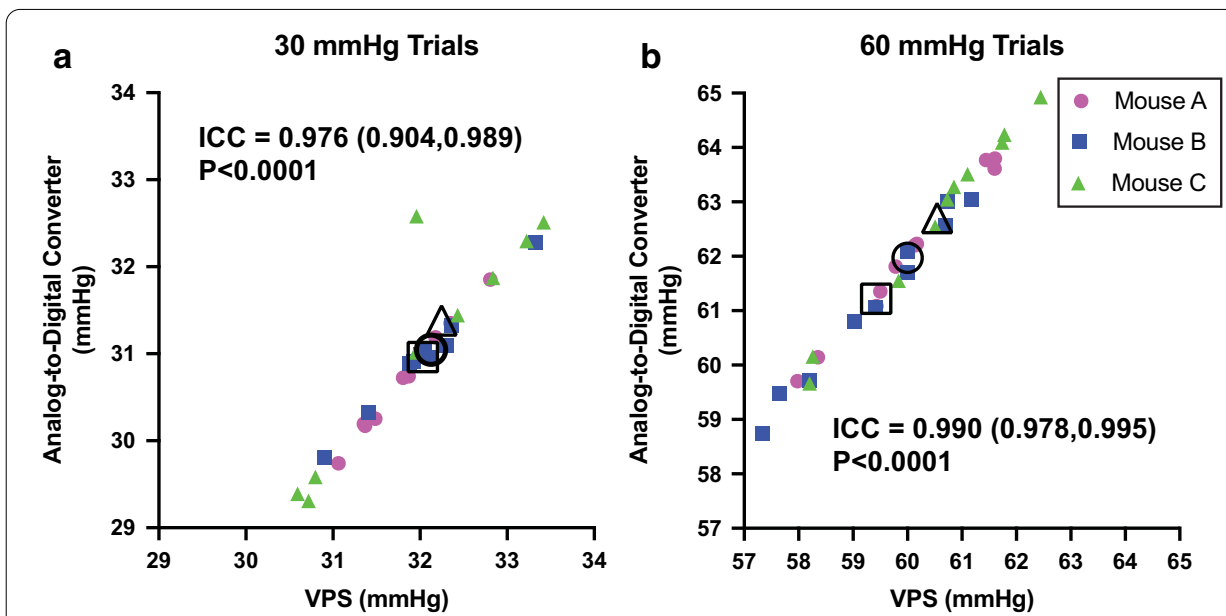

Fig. 5 Real-world comparison of pressure measured from VPS versus separate pressure meter. Data are presented from three different female mice (mice A, B, C). To compare the inter-rater reliability between the VPS pressure transducer and a separate pressure transducer in our analog-to-digital converter, data from multiple trials a at $30 \mathrm{mmHg}$ or $\mathbf{b} 60 \mathrm{mmHg}$ are plotted against each other for the two transducers. ICC (95\% confidence intervals) and $P$ values are provided for each graph. There is excellent reliability between the two transducers. Variability between trials within mice is due to variability in the manual adjustment of pressure that was done as trials alternated between 30 and $60 \mathrm{mmHg}$. Pressure target during manual adjustment was completed using a separate analog sphygmometer with a $\pm 3 \mathrm{mmHg}$ error. Large open symbols show mean pressure for that particular animal across all 10 trials

stimuli. This device was built using off-the-shelf parts and a Linux-based control system to facilitate rapid adoption in the research community. We built the system to be controlled via standard web protocols and the included example GUI. The GUI allows the researcher to quickly change the length of the pre-distention trial, the length of the actual distention trial, and the intertrial interval. By including a loop option, the system also allows a researcher to run multiple trials back-to-back. In addition, the control of the VPS instrument is automated using REST-based programmatic control, facilitating fully automated data collection systems. The inclusion of a stimulus marker output from the VPS allows for time-locking of the pressure stimulus to the EMG recorded in this experiment. However, this marker could easily be used for other physiological measurements (e.g., neuronal activity) and even behavior (e.g., locomotor activity captured with a video system). The system is also versatile and could easily include additional options including a trigger option and could be adapted to a fluid pump for delivery of liquid pressure stimuli. Python is the primary development language for the VPS system on both the user interface and on the embedded Linux system. This type of high-level and flexible language allows for quick changes and experimentation. Being cross-platform, the GUI works on Windows, Linux and Macintosh-based computers. Additionally, the fully featured embedded Linux system running on the VPS can support a vast array of programming languages from very low level $(\mathrm{C} / \mathrm{C}++/$ Rust $)$ to high-level applicationbased languages (MATLAB scripts via Octave) and everything in between.

This device provides an important modern update to the last publication of a pressure controller from 1987 [9]. That device used technology which necessitated multiple additional control devices all of which are subject to failure. Interestingly, there are certain elements of the original design that are still used. These, perhaps 
not surprisingly, are the ADC's used to measure air pressure and control the pinch valves. This technology has not significantly changed in the last 30 years. However, what has changed dramatically is the tremendous growth in the microcircuitry field. This growth allows for a significant amount of miniaturization in the present build. This miniaturization translates into cost savings for assembly time. What might previously have taken many tens of hours to build now takes less than an hour to assemble. Given that many older capacitors and switches are outdated, they can also be difficult to find if one fails. The current build uses mainly commercially available parts that are easily obtained providing a significant benefit in the time needed to procure parts.

To our knowledge, there are no commercially available units to control and measure pressure while including a stimulus marker for hollow organ distention experimentation. There are units to measure pressure of course (e.g., World Precision Instruments Model II-MRBP-M) that have been used in hollow organ pain testing in rodents [10, 11] but these units do not control air/liquid flow nor do they send stimulus markers for time-locking of experimental trials. Similarly, there are units designed to measure bladder function using cystometry (e.g., Med Associates Cystometry Station of Mouse Model CAT-CYT-M), but again, this is for measurement of bladder function not induction of pressure stimuli [12].

While there are no commercial comparisons to the VPS, there are reports in the literature of other custom units [13-15] or methods of pressure reading and recording $[16,17]$. To our knowledge, none of these other units are described in detail preventing a clear comparison of advantages and disadvantages to the VPS. We can however speak to the older custom machine (Washington University School of Medicine Electronics Shop) that our research group has used in the past $[6,7,18,19]$. This selfcontained unit relies on older Omron timers and rotary switches to select the taps to monitor the decade monitors. Push buttons (start, stop, pause, and reset) send a digital level signal to the various logic inputs to the panel and the internal digital logic to control the progression of trial sequences. The pressure pinch valve and transducer are equivalent to the VPS unit. While functionally similar to the VPS presented here, the older unit is difficult to troubleshoot. It also necessitates a considerable amount of manual wiring to build. This makes each unit significantly more time-consuming and costly to manufacture. Since the hardware is static and there is no software, the system is not as flexible for adapting to different experimental setups and requirements as the new VPS is with its off-the-shelf but modifiable circuitry and multiple operating system compatible software. An advantage of the older unit is that it is self-contained and does not require a separate computer to function. However, a computer is needed anyway to receive the signals from both models so that "disadvantage" of the VPS is negligible.

Overall, in this experiment we have described a valuable modern update to an important instrument used by biomedical researchers in the visceral pain field. This device has been designed for flexibility in use and is especially useful in conjunction with physiological experiments where time-locking of stimuli with pain measures is necessary. To ensure that other laboratories could duplicate this device, we have included the circuit diagram (Fig. 2), parts lists (Tables 1,2), and the code necessary to control the device (see Github repository https://github.com/lab-instruments). 
Table 1 Part list for VPS build

\begin{tabular}{|c|c|c|c|c|}
\hline Item & Catalog number & Quantity & Manufacturer & Notes \\
\hline \multicolumn{5}{|l|}{ Off-the-shelf components } \\
\hline $\begin{array}{l}\text { Cora Z7: Zynq-7000 } \\
\text { Single Core and Dual } \\
\text { Core Options for } \\
\text { ARM/FPGA SoC }\end{array}$ & 410-370-1 & 1 & Digilent & Main processing board \\
\hline $\begin{array}{l}\text { Pmod SSR: solid state } \\
\text { relay electronic switch }\end{array}$ & 410-342 & 1 & Digilent & $\begin{array}{l}\text { Relay to control the pinch } \\
\text { valve }\end{array}$ \\
\hline $\begin{array}{l}\text { Pmod AD1: Two 12-bit } \\
\text { A/D inputs }\end{array}$ & 410-064 & 1 & Digilent & ADC input \\
\hline $\begin{array}{l}\text { Pmod DA2: two 12-bit } \\
\text { D/A outputs }\end{array}$ & $410-113$ & 1 & Digilent & DAC output \\
\hline \multicolumn{5}{|l|}{ Power supply components } \\
\hline ups_pwr2 PCB & & 1 & OSHPARK & $\begin{array}{l}\text { https://oshpark.com/ } \\
\text { shared_projects/CstFkxbF }\end{array}$ \\
\hline $\begin{array}{l}\text { TERM BLK 2P SIDE ENT } \\
2.54 \mathrm{~mm} \text { PCB }\end{array}$ & 277-1273-ND & 1 & Phoenix Contact & Screw terminals for $12 \mathrm{VDC}$ \\
\hline $\begin{array}{l}\text { TERM BLK 6P SIDE } \\
\text { ENT } 2.54 \mathrm{~mm} \mathrm{PCB}\end{array}$ & 277-1277-ND & 1 & Phoenix Contact & Screw terminals for GND \\
\hline DC CONVERTER 5 V $5 \mathrm{~W}$ & 1951-2747-ND & 1 & Traco Power & $\begin{array}{l}\text { Primary } 12 \mathrm{VDC} \text { to } 5 \mathrm{VDC} \\
\text { converter }\end{array}$ \\
\hline \multicolumn{5}{|c|}{ Case and external connectors } \\
\hline $\begin{array}{l}\text { USB CIRCULAR CABLE } \\
\text { UNSEALED }\end{array}$ & SAM10681-ND & 1 & Samtec Inc & $\begin{array}{l}\text { For exposing the USB host } \\
\text { of the main processing } \\
\text { board }\end{array}$ \\
\hline $\begin{array}{l}\text { ADAPTER USB B RCPT } \\
\text { TO USB A RCPT }\end{array}$ & SAM8637-ND & 1 & Samtec Inc & $\begin{array}{l}\text { For exposing the USB serial } \\
\text { Linux terminal of the } \\
\text { main processing board }\end{array}$ \\
\hline $\begin{array}{l}\text { RJ45,C SIZE PANEL } \\
\text { SCREW 5E F CON }\end{array}$ & 1754-1125-ND & 1 & Amphenol LTW & $\begin{array}{l}\text { RJ45 Ethernet to the main } \\
\text { processing board }\end{array}$ \\
\hline $\begin{array}{l}\text { CONN PWR JACK } \\
2.5 \times 5.5 \mathrm{~mm} \text { SOLDER }\end{array}$ & SC1048-ND & 1 & Switchcraft Inc & 12VDC Power input \\
\hline $\begin{array}{l}\text { BOX ALUM GRAY } \\
4.88 " \mathrm{~L} \times 7.13 " \mathrm{~W}\end{array}$ & HM2530-ND & 1 & $\begin{array}{l}\text { Hammond Manufactur- } \\
\text { ing }\end{array}$ & Main box \\
\hline $\begin{array}{l}\text { LED PNL IND } 7 \text { mm GRN } \\
\text { INTERNL }\end{array}$ & 350-2924-ND & 1 & Dialight & Power indicator light \\
\hline $\begin{array}{l}\text { SWITCH ROCKER SPST } \\
10 \mathrm{~A} 125 \mathrm{~V}\end{array}$ & EG1889-ND & 1 & E-Switch & Power switch \\
\hline $\begin{array}{l}\text { FUSE HLDR CART } 250 \mathrm{~V} \\
\text { 10A PNL MNT }\end{array}$ & F3125-ND & 1 & Littelfuse Inc & Fuse holder for protection \\
\hline $\begin{array}{l}\text { FUSE GLASS 4A 125VAC } \\
5 \times 20 \mathrm{~mm}\end{array}$ & F4729-ND & 1 & Littelfuse Inc & Fuse for protection \\
\hline \multicolumn{5}{|c|}{ DAC/ADC connectorized board } \\
\hline $\begin{array}{l}\text { Ups analog interface } \\
\text { PCB }\end{array}$ & & 1 & & $\begin{array}{l}\text { https://oshpark.com/ } \\
\text { shared_projects/eoxPS4Tj }\end{array}$ \\
\hline $\begin{array}{l}\text { RES SMD } 0 \Omega \text { JUMPER } \\
\text { 1/8 W } 0805\end{array}$ & 311-0.0ARCT-ND & 20 & Yageo (VA) & Board mount jumpers \\
\hline $\begin{array}{l}\text { CONN SMA JACK R/A } 50 \\
\Omega P C B\end{array}$ & A97593-ND & 2 & $\begin{array}{l}\text { TE Connectivity AMP } \\
\text { Connectors }\end{array}$ & $\begin{array}{l}\text { Board mount, right angle } \\
\text { SMA connectors }\end{array}$ \\
\hline $\begin{array}{l}\text { CONN HEADER VERT } \\
\text { 6POS } 2.54 \mathrm{~mm}\end{array}$ & SAM1029-06-ND & 2 & Samtec Inc & $\begin{array}{l}\text { Pmod to connectorized } \\
\text { board connection bus }\end{array}$ \\
\hline Pressure sensor & SPD002GAsil & 1 & Smartec & Pressure transducer sensor \\
\hline \multicolumn{5}{|l|}{ Misc connectors and parts } \\
\hline 1/4 HEX $\times 1 / 2$ LENGTH & 1772-2591-ND & 15 & RAF Electronic Hardware & $\begin{array}{l}\text { Standoffs for board mount- } \\
\text { ing }\end{array}$ \\
\hline $\begin{array}{l}\text { MACHINE SCREW PAN } \\
\text { PHILLIPS 6-32 }\end{array}$ & 36-9903-ND & 15 & Keystone Electronics & Screws for board mounting \\
\hline
\end{tabular}


Table 1 (continued)

\begin{tabular}{lllll}
\hline Item & Catalog number & Quantity & Manufacturer & Notes \\
\hline $\begin{array}{c}\text { Pmod Cable Kit: 6-pin } \\
\text { 6" }\end{array}$ & $240-021-6$ & 1 & Digilent & $\begin{array}{c}\text { Pmod cable to connect } \\
\text { main board to Pmod }\end{array}$ \\
$\begin{array}{c}2 \times 6 \text {-pin to Dual 6-pin } \\
\text { Pmod Splitter Cable }\end{array}$ & $240-110$ & 1 & Digilent & $\begin{array}{c}\text { Pmod cable to connect } \\
\text { main board to Pmod }\end{array}$ \\
$\begin{array}{c}\text { Pmod Clip: Mechani- } \\
\text { cal Mount for Pmod } \\
\text { boards }\end{array}$ & $240-107$ & 1 & Digilent & Pmod mount clip \\
\begin{tabular}{c} 
12V, 3A power supply \\
\hline
\end{tabular} & $240-057$ & 1 & Digilent & Main 12VDC supply \\
\hline
\end{tabular}

Table 2 Inline analog-to-digital pressure converter

\begin{tabular}{llll}
\hline Item & Catalog number & Quantity & Manufacturer \\
\hline Platinum Series Digital panel meter & DP8PT-006 & 1 & Omega \\
Pressure transducer & PX309-005GV & 1 & Omega \\
1402 series instrument case & $1402 \mathrm{~K}$ & 1 & Hammond \\
\hline
\end{tabular}

\section{Methods}

\section{Circuit design}

The circuit diagram for the VPS is shown in Fig. 2.

\section{VPS construction}

Off-the-shelf items for the VPS build can be found in Table 1. The majority of the parts are available off the shelf and use with only minor modifications. A custom board was designed to connectorized the ADC and DAC. The board adds a footprint for the pressure transducer for the input to the ADC and two SMA connectors for voltage output from the DAC. The ADC and DAC Pmod boards were modified by removing their normal input/output connectors and soldering directly to the connectorized board. A custom power supply was built to convert from 12 to $5 \mathrm{v}$ for the FPGA board and provide $12 \mathrm{v}$ power to control the pinch valve. All of the parts were put into a metal project box and the necessary connections are broken out to panel mount connectors including the RJ45 Ethernet connector, USB host, USB device, 12v power input, fuse holder, air inputs/ outputs/vents, power switch, power LED indicator, BNC control voltage output and BNC proportional voltage output. The VPS has a total of 4 inlet/outlets (Fig. 1a). One is for the air intake. This air intake is connected to a compressed air tank with an analog pressure control valve used to regulate air input to the VPS (Fig. 3). A second outlet is an exhaust valve for quick reset of the system at the end of a trial. The third and fourth valves are outlets for the air stimulus to the mouse catheter.

\section{Coding and software}

The code for all parts of the project is available under the Github repository https:// github.com/lab-instruments. The code is broken into the platform firmware and the desktop GUI. All code is released under the MIT license. 
The platform firmware is located under the repository located at https://github.com/ lab-instruments/ups. This repository provides the necessary source code and scripts to completely build from source the embedded Linux, u-boot and FPGA binary. The repository also includes the Python servers and embedded platform startup scripts. To build the platform code, a Linux (tested on Ubuntu) PC, Xilinx Vivado 2018.2 and various packages are required. The script located at ups/init/init_box.sh can setup and install all required software. The build (u-boot, embedded Linux and the FPGA code) is fully scripted and automated including TCL based FPGA development tool automation and SD card creation and writing (for the FPGA board). The FPGA code is written using standard System Verilog and industry standard coding methods. The embedded Linux was built using the Buildroot tool and a custom configuration script.

The GUI software with installation instructions is located under the repository located at https://github.com/lab-instruments/ups_python. The GUI is written in pure python and requires Python3. To run the GUI, you need Python3 and various other libraries installed. These libraries include (1) "PyQt5" (GUI libraries; https://pypi.org/project/ PyQt5/), (2) "netifaces" (library to examine hardware network interfaces; https://pypi. org/project/netifaces/), and (3) "requests" (an HTTP interrogation library; https://pypi. org/project/requests/). A setup script called ups_python/python/setup_venv.sh sets up a Python virtual environment with all the required dependencies. The ups_python/ python/gui.sh utilizes the virtual environment setup by setup_venv.sh and launches the GUI. The GUI is cross-platform and should run on any PC or Mac that supports Python3 and PyQT5.

\section{Animal experimentation}

Animal usage was approved by the University of Texas at Dallas Institutional Animal Care and Use Committee. For the primary demonstration of the unit, one female C57 $\mathrm{Bl} / 6 \mathrm{~J}$ mouse (adult 12 weeks old) was used in this study. We also included data from three additional mice (female $\mathrm{C} 57 \mathrm{Bl} / 6 \mathrm{~J}$ adult 12 weeks old) that were used in real-world experiments as described below to compare the pressure measured read by the VPS and the pressure from our digital-to-analog converter. The visceromotor response (VMR) is a spinobulbospinal reflex and quantitative measure of these pain-like responses. VMRs are obtained by measuring the electrical activity (EMG) of the external oblique abdominal muscle during bladder distension; this EMG is a reliable, reproducible measure of nociception that is exacerbated by bladder sensitization and reduced following analgesic administration [20]. In these experiments, UBD was performed as previously reported $[6,7,19]$ (Fig. 3). Briefly, mice were anesthetized with isoflurane in an induction chamber then transferred to a nose cone administering $2 \%$ isoflurane (vaporized with $100 \%$ $\mathrm{O}_{2}$ ). An incision was made in the lower skin of the abdomen and two silver wires were implanted in the left abdominal muscle. A third grounding wire was laced through the skin overlying the chest cavity. Lastly, a lubricated 24 gauge, $14 \mathrm{~mm}$ angiocatheter was inserted in the bladder via the urethra.

Following surgical completion, isoflurane was lowered to $1.5 \%$ for $10 \mathrm{~min}$. Isoflurane was then gradually lowered by an additional $0.125 \%$ every 10 min until animals responded to noxious toe pinch but were not vocalizing or ambulating (typically $0.8-$ $0.875 \%)$. Once at a stable isoflurane level, animals' bladders were distended three times 
Table 3 Comparison of pressure outputs for demonstration trials

\begin{tabular}{lllllll}
\hline Trial \# & $\begin{array}{l}\text { Target } \\
\text { pressure } \\
(\mathrm{mmHg})\end{array}$ & $\begin{array}{l}\text { Analog } \\
\text { Sphyg. } \\
(\mathrm{mmHg})\end{array}$ & $\begin{array}{l}\text { VPS } \\
(\mathrm{mean} \pm \mathrm{SD}) \\
(\mathrm{mmHg})\end{array}$ & $\begin{array}{l}\text { Analog-to-digital } \\
\text { converter }(\text { mean } \pm \mathrm{SD}) \\
(\mathrm{mmHg})\end{array}$ & $\begin{array}{l}\text { MatLab avg } \\
\text { pressure from VPS } \\
\text { signal }\end{array}$ & $\begin{array}{l}\text { MatLab VMR } \\
\text { signal (V* } \mathrm{s})\end{array}$ \\
\hline 1 & 30 & $31 \pm 3$ & $32.92 \pm 0.53$ & $32.15 \pm 0.70$ & 32.83 & 1.33 \\
2 & 30 & $31 \pm 3$ & $32.98 \pm 0.57$ & $32.16 \pm 0.78$ & 32.95 & 1.59 \\
3 & 30 & $32 \pm 3$ & $32.34 \pm 0.84$ & $31.17 \pm 1.16$ & 32.33 & 1.22 \\
\hline
\end{tabular}

Data show pressure and calculated VMR for 3 trials ( $20 \mathrm{~s}$ of actual stimulus; total trial length $40 \mathrm{~s}$; intertrial interval of $1 \mathrm{~min}$ ) between the VPS, the inline analog-to-digital pressure converter and a commercial analog sphygmometer. The Matlab avg pressure was calculated from VPS signal and the Matlab VMR signal was calculated from the normalized EMG signal

with $30 \mathrm{mmHg}$ compressed air. A y-splitter in the VPS-to-catheter tubing was used to independently measure pressure during stimuli for comparison to the pressure reader in the VPS. Two different devices were used to independently measure the pressure. This included a commercial analog sphygmometer (Criterion Model 85G, Prestige Medical with a manufacturer set tolerance of $\pm 3 \mathrm{mmHg}$ ) and a custom inline analog-to-digital pressure converter (Table 2). The converter consisted of a pressure transducer (Omega Manufacturing, Model PX309-005GV) and a calibrated pressure reader (Omega Manufacturing, Model DP8PT-006) with a BNC output to an ADC input on a Micro1401-4 (Cambridge Electronic Design (CED)).

Two BNC outputs from the VPS were connected to ADC inputs on the Micro1401-4. Each distension lasted $20 \mathrm{~s}$ with a 1 min intertrial interval (ITI). The VMR signal was relayed in real-time using a preamplifier (World Precision Instruments ISO-80) connected to the Micro1401-4. The Micro1401-4 was connected to a PC equipped with Spike2 data acquisition software (Version 8, CED).

\section{Demonstration data}

Demonstration mouse was given three $20 \mathrm{~s}$ distention trials targeted at $30 \mathrm{mmHg}$ with $1 \mathrm{~min}$ in between trials. The actual air pressure is controlled with a dial and analog sphygmometer. Thus, while $30 \mathrm{mmHg}$ is the target pressure, the actual pressure (measured in a trial from the VPS and secondary analog-to-digital pressure converter) is always slightly off from the target (as seen in Table 3). $30 \mathrm{mmHg}$ is thought to be relatively innocuous while still eliciting a VMR (similar to filling of the bladder after drinking a cup of coffee). Raw data was exported individually from each trial starting $\sim 0.5-0.75 \mathrm{~s}$ prior to the predistention signal marker to plot raw data (Fig. 4). When plotting these data, $x$-axis was manually adjusted so that all three trial pre-distention marker signals matched. Pressure read on Spike2 by the VPS and the digital-to-analog converter were analyzed in Spike2 to determine the average pressure across each trial. In addition, all data from the experiment including background data between trials was exported from Spike2 for analysis of VMR. VMR signal was subtracted from background EMG activity, rectified, and integrated over the distension periods, as previously described [6, 19], using a custom script written in MatLab (MathWorks). To normalize, all distension VMRs were divided by the smallest pre-distension VMR for the individual experiment. 


\section{Real-world experimentation}

After a successful demonstration of the device in a wild-type mouse, we sought to utilize the VPS in our real-world laboratory experiments. Over the course of a 2-month period, we used the system described here for 18 mice. The total number of trials completed with the VPS (and other system components described above) was 1200. Here, we have analyzed pressure data from three of these mice to further validate the VPS system. These mice received alternating $20 \mathrm{~s}$ pressure trials of 30 and $60 \mathrm{mmHg}$ with $1 \mathrm{~min}$ in between trials. Targeted $60 \mathrm{mmHg}$ pressure is thought to be noxious (similar to a full bladder). We report 20 total trials per animal (10 at $30 \mathrm{mmHg}$ and 10 at $60 \mathrm{mmHg}$ ). Pressure data were processed and analyzed as above in Spike 2 for the demonstration trials. $30 \mathrm{mmHg}$ and $60 \mathrm{mmHg}$ data were separately analyzed using SPSS (v 1.0.0.1406) and plotted with Prism (v 8.0) to determine intra-rater reliability using an intra-class correlation coefficient (ICC). See Additional file 1 for the raw data from these trials.

Abbreviations

EMG: Electromyogram; GUI: Graphic user interface; ICC: Intraclass correlation coefficient (ICC); UBD VMR: Urinary bladder distention visceromotor response; VPS: Visceral pain stimulator.

\section{Supplementary Information}

The online version contains supplementary material available at https://doi.org/10.1186/s12938-021-00870-y.

Additional file 1. This is the raw data used for Figure 4 and 5.

\section{Acknowledgements}

We acknowledge Dr. Benjamin Goldschmidt for early consultation on this project. We acknowledge Heather Allen for statistical assistance. Figure 3 was created with Biorender. This research was supported by a NIH Grant to BJK (NIH NIDDK R01 DK115478) with supplement to MGS (NIH NIDDK R01 DK115478S1).

\section{Authors' contributions}

MD designed and built electronics; MD wrote code associated with device; MD and BJK tested device; MGS and VMH tested VPS in animals; OB and MGS developed analysis script; MGS, VMH, and OB edited manuscript; MD and BJK wrote and edited manuscript. All authors read and approved the final manuscript.

\section{Authors' information}

MD-electrical engineer and computer scientist with 20 years of experience in hardware and software development at Fortune 500 companies. BJK-neurobiologist with 20 years of experience in academic biomedical research including 12 years of experience studying bladder pain in animal models.

\section{Funding}

Funding for this research was provided by the National Institutes of Health (BJK-NIH DK115478; MGS-NIH DK115478S1).

\section{Availability of data and materials}

Raw data from three UBD-VMR trials is included in Additional file 1. Code for VPS and VMR-UBD analysis script (MatLab) can be found at https://github.com/lab-instruments.

\section{Declarations}

Ethics approval and consent to participate

Animal testing as presented was approved by The University of Texas at Dallas Institution Animal Care and Use Committee (Protocol 20-04).

\section{Consent for publication}

All authors consent to publication.

\section{Competing interests}

The authors have no competing financial interests to declare.

\section{Author details}

${ }^{1}$ Center for Advanced Pain Studies, Department of Neuroscience, University of Texas at Dallas, 800 W. Campbell Rd., Richardson, TX 75080, USA. ${ }^{2}$ Department of Biological Sciences, Duquesne University, 600 Forbes Avenue, Pittsburgh, PA 15217, USA. 
Received: 6 January 2021 Accepted: 16 March 2021

Published online: 25 March 2021

\section{References}

1. Cervero F. Visceral versus somatic pain: similarities and differences. Dig Dis. 2009;27(Suppl 1):3-10. https://doi.org/ $10.1159 / 000268115$

2. Gebhart GF, Bielefeldt K. Physiology of visceral pain. Compr Physiol. 2016;6:1609-33. https://doi.org/10.1002/cphy. C150049.

3. Inadomi JM, Fennerty MB, Bjorkman D. Systematic review: the economic impact of irritable bowel syndrome. Aliment Pharmacol Ther. 2003;18:671-82. https://doi.org/10.1046/j.0269-2813.2003.01736.x.

4. Polackwich AS, Shoskes DA. Chronic prostatitis/chronic pelvic pain syndrome: a review of evaluation and therapy. Prostate Cancer Prostatic Dis. 2016;19:132-8. https://doi.org/10.1038/pcan.2016.8.

5. Czakanski UWPP. Pelvic pain: a chronic visceral pain syndrome. Curr Pain Headache Rep. 2001;5:13-9.

6. Sadler KE, Stratton JM, Kolber BJ. Urinary bladder distention evoked visceromotor responses as a model for bladder pain in mice. J Vis Exp. 2014. https://doi.org/10.3791/51413.

7. Sadler KE, Stratton JM, Deberry JJ, et al. Optimization of a pain model: effects of body temperature and anesthesia on bladder nociception in mice. PLoS ONE. 2013;8:e79617. https://doi.org/10.1371/journal.pone.0079617.

8. Ness TJ, Gebhart GF. Visceral pain: a review of experimental studies. Pain. 1990;41:167-234.

9. Anderson RH, Ness TJ, Gebhart GF. A distension control device useful for quantitative studies of hollow organ sensation. Physiol Behav. 1987;41:635-8.

10. Srivastava $\mathrm{P}$, Lai HH, Mickle AD. Characterization of a method to study urodynamics and bladder nociception in male and female mice. Low Urin Tract Symptoms. 2020. https://doi.org/10.1111/luts.12365.

11. Dmitrieva N, Faircloth EK, Pyatok S, et al. Telemetric assessment of referred vaginal hyperalgesia and the effect of indomethacin in a rat model of endometriosis. Front Pharmacol. 2012;3:158. https://doi.org/10.3389/fphar.2012. 00158.

12. Iguchi N, Malykhina AP, Wilcox DT. Early life voiding dysfunction leads to lower urinary tract dysfunction through alteration of muscarinic and purinergic signaling in the bladder. Am J Physiol Renal Physiol. 2018;315:F1320-8. https://doi.org/10.1152/ajprenal.00154.2018

13. Lai HH, Qiu CS, Crock LW, et al. Activation of spinal extracellular signal-regulated kinases (ERK) $1 / 2$ is associated with the development of visceral hyperalgesia of the bladder. Pain. 2011;152:2117-24. https://doi.org/10.1016/j.pain. 2011.05.017.

14. Pierce AN, Di Silvestro ER, Eller OC, et al. Urinary bladder hypersensitivity and dysfunction in female mice following early life and adult stress. Brain Res. 2016;1639:58-73. https://doi.org/10.1016/j.brainres.2016.02.039.

15. Ji Y, Murphy AZ, Traub RJ. Estrogen modulates the visceromotor reflex and responses of spinal dorsal horn neurons to colorectal stimulation in the rat. J Neurosci. 2003;23:3908-15.

16. Brenner L, Zerlin L, Tan LL. Functional disruption of cortical cingulate activity attenuates visceral hypersensitivity and anxiety induced by acute experimental colitis. Sci Rep. 2021:11:2103. https://doi.org/10.1038/s41598-021-81256-x.

17. Ness TJ, Gebhart GF. Inflammation enhances reflex and spinal neuron responses to noxious visceral stimulation in rats. Am J Physiol Gastrointest Liver Physiol. 2001:280:G649-657. https://doi.org/10.1152/ajpgi.2001.280.4.G649.

18. Crock LW, Kolber BJ, Morgan CD, et al. Central amygdala metabotropic glutamate receptor 5 in the modulation of visceral pain. J Neurosci. 2012;32:14217-26. https://doi.org/10.1523/JNEUROSCI.1473-12.2012.

19. Sadler KE, McQuaid NA, Cox AC, et al. Divergent functions of the left and right central amygdala in visceral nociception. Pain. 2017:158:747-59. https://doi.org/10.1097/j.pain.0000000000000830.

20. Ness TJ, Elhefni H. Reliable visceromotor responses are evoked by noxious bladder distention in mice. J Urol. 2004:171:1704-8

\section{Publisher's Note}

Springer Nature remains neutral with regard to jurisdictional claims in published maps and institutional affiliations.

Ready to submit your research? Choose BMC and benefit from:

- fast, convenient online submission

- thorough peer review by experienced researchers in your field

- rapid publication on acceptance

- support for research data, including large and complex data types

- gold Open Access which fosters wider collaboration and increased citations

- maximum visibility for your research: over 100M website views per year

At BMC, research is always in progress.

Learn more biomedcentral.com/submissions 